Department of

Genetics, University of

Leicester, Leicester

LE1 7RH, UK

S N J Jackson

R C Trembath

Department of

Medicine, Leicester

Royal Infirmary NHS

Trust, Leicester

LE1 5WW, UK

S N J Jackson

B Williams

Department of

Medicine and

Therapeutics,

University of Leicester,

Leicester LE1 7RH,

UK,

P Houtman

Children's Hospital, Leicester Royal Infirmary NHS Trust, Leicester LE1 5WW, UK

R C Trembath

Correspondence to: Professor Trembath.

Received 31 July 1997

Revised version accepted for publication

1 December 1997

\section{The diagnosis of Liddle syndrome by identification of a mutation in the $\beta$ subunit of the epithelial sodium channel}

\author{
Stephen N J Jackson, Bryan Williams, Peter Houtman, Richard C Trembath
}

\begin{abstract}
Hypertension is a common multifactorial disorder associated with considerable morbidity and mortality. The kidney plays a major role in the long term regulation of blood pressure. Liddle syndrome (pseudohyperaldosteronism) is one of a number of monogenic disorders of salt and water transport. In a kindred with at least four affected members suffering from Liddle syndrome, we confirmed by direct DNA sequencing the identity of a novel heterozygous mutation in hßENaC, the gene encoding the $\beta$ subunit of the amiloride sensitive epithelial sodium channel which is expressed in the distal nephron. Single stranded conformational polymorphism analysis showed cosegregation of the mutant allele within the kindred with the Liddle phenotype. An insertion of an additional cytosine into a string of six located between codons 593 and 595 results in a sequence frameshift and is
\end{abstract}

predicted to produce a protein truncated by 34 amino acids. The availability of a molecular diagnostic tool has implications for the management of hypertension and genetic counselling in families with Liddle syndrome.

(F Med Genet 1998;35:510-512)

Keywords: Liddle syndrome; $h \beta E N a C$

Liddle syndrome (pseudohyperaldosteronism), one of a number of monogenic disorders of salt and water transport, ${ }^{1}$ first described in $1963,{ }^{2}$ is an autosomal dominant disorder leading to systemic hypertension, hypokalaemia, and alkalosis in the presence of inappropriately low serum renin and mineralocorticoid (aldosterone). Raised blood pressure is associated with excessive sodium reabsorption through the amiloride sensitive epithelial sodium channels $(\mathrm{ENaC})$ in the distal nephron. Aldosterone acts via the mineralocorticoid receptor to increase the open probability of $\mathrm{ENaC}$ and may increase the number of channels present at the apical membrane, thereby leading to an increase in sodium flux and a consequent increase in systemic blood pressure. $^{3}$ Onset of hypertension in Liddle syndrome is typically in childhood and, if unrecognised, can lead to renal failure in the fourth or fifth decades of life. Treatment with mineralocorticoid antagonists such as spironolactone is ineffective. Amiloride, however, will normalise the blood pressure and the associated biochemical abnormalities. This drug is known to act directly upon $\mathrm{ENaC}$ as shown by its ability to extinguish sodium flux through the channel when expressed in Xenopus oocytes. ${ }^{4}$ Three other disorders will produce hypertension and biochemical findings similar to Liddle syndrome. Distinction between these disorders is important as their response to medical therapy differs. Primary hyperaldosteronism is an acquired disorder and differs from Liddle syndrome in the associated inappropriately raised serum aldosterone. Appropriate management involves identification of the site of excess aldosterone secretion and its elimination. In contrast, apparent mineralocorticoid excess (AME) presents in childhood and is caused by a congenital deficiency of $11 \beta$ hydroxysteroid dehydrogenase type I activity. This enzyme converts cortisol to cortisone and maintains specificity of the renal mineralocorticoid receptor for aldosterone. ${ }^{6}$ Spironolactone is the treatment of choice in this disorder. Glucocorticoid remediable aldosteronism ${ }^{7}$ is an autosomal dominant condition resulting from unequal crossing over analysis was used to assess segregation of the sequence variant in the family. Pedigree and SSCP analysis of PCR product obtained from amplification of $249 \mathrm{bp}$ of the ter
exon of $h \beta E N a C$ using the primers (5' to 3') CTTGGCCAAGAGCCTACG and ATGGCATCACCCTCACTGT are shown. Filled symbols represent affected subjects. The subject represented by a shaded symbol was treated for hypertension. The mutant allele is present in the father and all three offspring but not present in the unaffected mother. SSCP analysis was performed as previously described except for the maintenance of a gel temperature of $15^{\circ} \mathrm{C} .^{13}$ 
Table 1 Results of clinical investigations. Serum aldosterone and plasma renin activity are estimated by radioimmunoassay

\begin{tabular}{llllll}
\hline Subject & $\begin{array}{l}\text { BP before } \\
\text { treatment } \\
(\mathrm{mm} \mathrm{Hg})\end{array}$ & $\begin{array}{l}\text { Serum } K^{+} \\
(\text {mmolll) }\end{array}$ & $\begin{array}{l}\text { Renin activity } \\
(\text { pmoll/) } \\
\text { NR=1.1-4.5 }\end{array}$ & $\begin{array}{l}\text { Serum aldosterone } \\
(\text { pmoll) }) \\
\text { NR=100-500 }\end{array}$ & $\begin{array}{l}\text { BP after } \\
\text { treatment } \\
(\mathrm{mm} \mathrm{Hg})\end{array}$ \\
\hline Proband & $142 / 100$ & 3.0 & $<0.2$ & 80 & $110 / 80$ \\
Sib 1 & $152 / 59$ & & $<0.2$ & 60 & $110 / 80$ \\
Sib 2 & $120 / 80$ & 3.7 & $<0.2$ & 55 & $120 / 86$ \\
Father & $130 / 94$ & 3.7 & 1.3 & 50 & \\
\hline
\end{tabular}

$\mathrm{NR}=$ normal range.

leading to fusion of the promoter of the CYP11B1 gene to the coding sequence of the aldosterone synthase gene. ${ }^{8}$ It is treated with oral glucocorticoids.

Liddle syndrome is caused by constitutive activation of $\mathrm{ENaC}$ as first proposed because of a lack of demonstrable excess mineralocorticoid activity in combination with a reduction in blood pressure following treatment with amiloride. The epithelial sodium channel is expressed in the distal nephron and composed of an $\alpha, \beta$, and $\gamma$ subunit. ${ }^{9}$ The three proteins share $32-37 \%$ identity in amino acid sequence. ${ }^{10}$ Each has two transmembrane domains separated by a long extracellular domain and an amino- and carboxy-terminal intracytoplasmic domain. The $\alpha$ subunit is able to support sodium conductance by itself. The $\beta$ and $\gamma$ channels greatly augment this conductance but do not allow the passage of sodium independent of the $\alpha$ subunit. The genes encoding the $\beta$ and $\gamma$ subunits lie within a $400 \mathrm{~kb}$ region on the short arm of chromosome 16 (16p13-p12) while the $\alpha$ subunit gene is located at chromosome $12 \mathrm{p} 13$.

Shimkets et $a l^{11}$ recently reported linkage to an intragenic GT repeat polymorphism of $\mathrm{h} \beta \mathrm{ENaC}$. Direct sequencing in five independent kindreds showed the presence of four different mutations, namely two premature stop codons and two frameshift mutations in the carboxy-terminal domain of the $\beta$ subunit gene. Interestingly, an indistinguishable phenotype may be caused by mutation of the carboxy-terminal end of the $\gamma$ subunit of the epithelial sodium channel. ${ }^{12}$

As only a small number of $\mathrm{ENaC}$ mutations have so far been identified, and given the importance of confirmation of the diagnosis in order to tailor the specific therapy, we performed molecular analysis of the $\mathrm{h} \beta \mathrm{ENaC}$ gene in a British family containing two sibs presenting with significant hypertension in childhood. The proband (III.1, fig 1) was first noted to be hypertensive aged 11 when examined following a minor road traffic accident. Her father (II.1) and paternal grandfather (I.1) were said to have a history of essential hypertension, the former having been prescribed bendrofluazide, an appropriate agent for essential hypertension, but with the potential effect of exacerbating the hypokalaemia typical of Liddle syndrome. Subsequent blood pressure estimations performed on her two sibs showed one to be hypertensive (III.2) and the other to be borderline hypertensive (III.3) (table 1). Clinical investigation yielded results compatible with the diagnosis of Liddle syndrome in the proband (III.1), her father (II.1), and her hypertensive brother (III.2) (table 1). Treatment with amiloride was started for II.1, III.1, and III.2 leading to adequate control of the hypertension. The youngest offspring (III.3), aged 9 years, remains under observation with borderline hypertension. The mother was normotensive.

Three of the four previously identified mutations within the carboxy-terminal domain of the $\beta$ subunit were excluded from having a role in the aetiology of Liddle syndrome in this family through restriction digest analysis of PCR

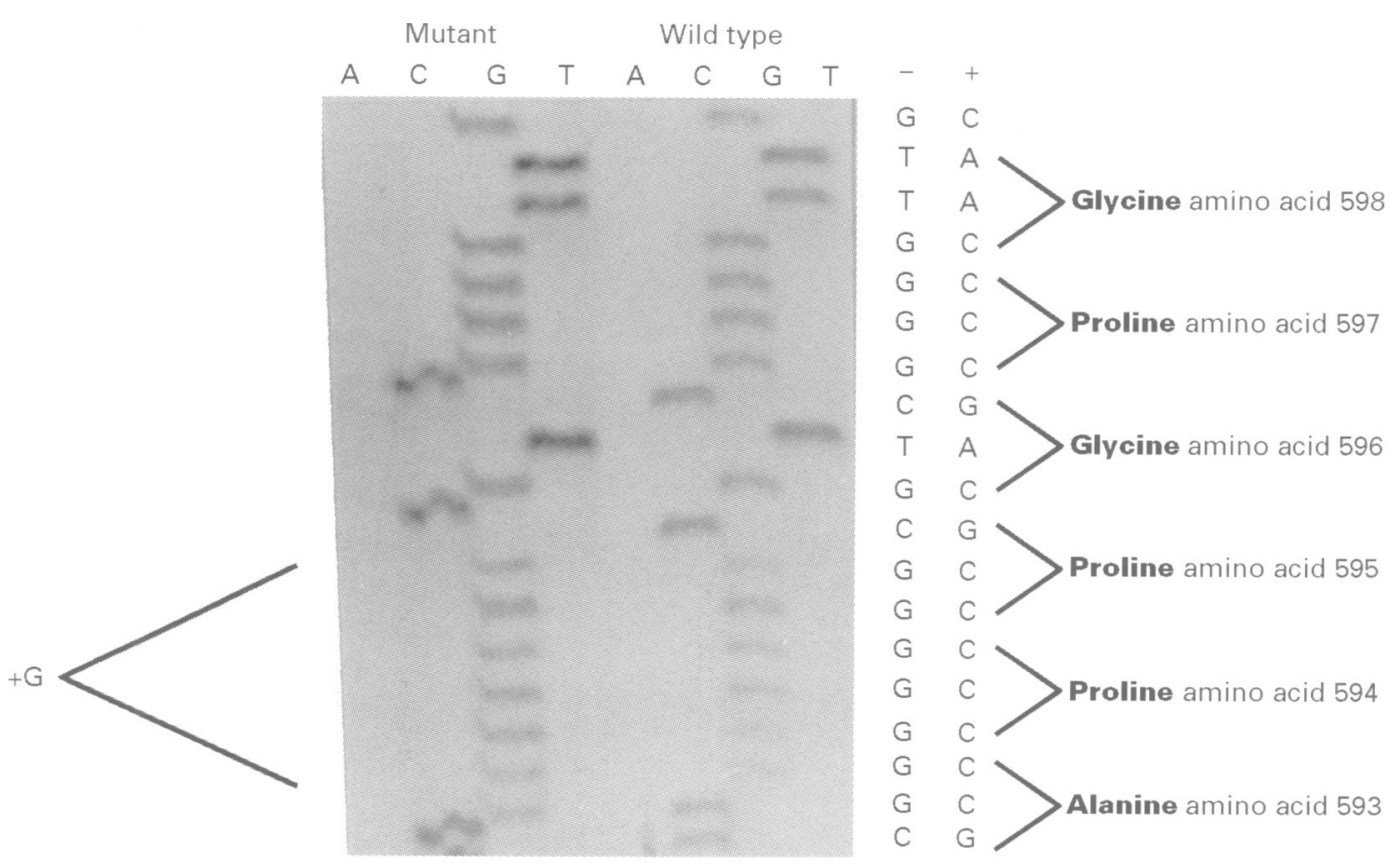

Figure 2 Sequence data generated from cloned PCR product from II.2. The reverse strand is shown and the derived sequence of the sense $(+)$ strand of the mutant allele is included. An additional guanine is present in the mutant allele, corresponding to a cytosine in the sense strand. This leads to a predicted change of protein sequence starting at amino acid 595, proline being substituted for the wild type arginine. PCR product from II. 2 was cloned into TOP1OF'cells using an Invitrogen $^{T M}$ kit according to the manufacturer's instructions. Sequencing reactions were performed radioactively using the oligonucleotide primer ATGGCATCACCCTCACTGT and a dideoxy-terminator protocol. 
products (data not shown). Single stranded conformational polymorphism (SSCP) analysis showed a sequence variant in the proband, her father, and both sibs not seen in the mother or normal controls, implicating the $\beta$ subunit as the potential site of mutation (fig 1). Direct sequencing of genomic DNA suggested the presence of a heterozygous insertion of an additional cytosine into a string of six cytosines between codons 593 and 595. Confirmation was achieved by direct sequencing of PCR product from colonies containing single alleles of the amplified segment (fig 2). The mutation is predicted to lead to a frameshift with a protein product 34 amino acids shorter than wild type.

This is only the fifth reported mutation in the $\beta$ subunit of the epithelial sodium channel producing the Liddle phenotype, all of the mutations occurring in the carboxy-terminal domain and leading to frameshifts of the reading frame. One other kindred has been identified with a single base substitution mutation in the $\gamma$ subunit leading to a truncation of the last 76 amino acids. The importance of the carboxy-terminal domains of the $\beta$ subunit of $\mathrm{ENaC}$ has been shown ex vivo by Snyder et $a l^{4}$ who expressed mutant $\beta$ subunit protein with wild type $\alpha$ and $\gamma$ subunits, showing that without a conserved motif, amino acids 616-623, the sodium current is increased compared with non-chimaeric channels secondary to an increase in surface expression of $\mathrm{ENaC}$ owing to a slower rate of internalisation from the cell membrane as well as to an increase in the open probability of the channel.

The mutation identified in the present kindred is predicted to generate a protein product containing none of this conserved region. By confirming the diagnosis of Liddle syndrome using the molecular techniques described, antihypertensive therapy may be tailored directly at the causative ion channel defect using the drug amiloride. The presence of the disease mutation in the youngest offspring (III.3) with borderline hypertension confirms the need for careful clinical assessment and allows tailoring of specific therapy in the event of future hypertension. ${ }^{14}$

Funding from Leicester Royal Infirmary NHS Trust Training Fellowship (SJ) is gratefully acknowledged. We thank Dr Beth Coyle, Dr Micheala Aldred, Dr Raymond Dalgleish, Colin Veal, and Wendy Merrison for technical assistance.

1 Lifton RP. Molecular genetics of human blood pressure regulation. Science 1996;272:676-80.

2 Liddle GW, Bledsoe T, Coppage WS Jr. A familial renal disorder simulating primary aldosteronism but with negligible aldosterone secretion. Trans Assoc Am Phys 1963;76:199213.

3 Kleyman TR, Ernst SA, Coupaye-Gerard B. Arginine vasopressin and forskolin regulate apical cell surface expression of epithelial $\mathrm{Na}^{+}$channels in $\mathrm{A} 6$ cells. $\mathrm{Am} \mathscr{f}$ Physiol 1994;266:F506-11.

4 Snyder PM, Price MP, McDonald FJ, et al. Mechanisms by which Liddle's syndrome mutations increase activity of a which Liddle's syndrome mutations increase activity
human epithelial $\mathrm{Na}^{+}$channel. Cell 1995;83:969-78.

5 Ulick S, Levine LS, Gunczler P, et al. A syndrome of apparent mineralocorticoid excess associated with defects in the peripheral metabolism of cortisol. F Clin Endocrinol Metab 1979;49:757-64.

6 Funder JW, Pearce PT, Smith R, Smith AI. Mineralocorticoid action: target tissue specificity is enzyme, not receptor, mediated. Science 1988;242:583-5.

7 Giebink GS, Gotlin RW, Biglieri EG, Katz FH. A kindred with familial glucocorticoid-suppressible aldosteronism. $\mathcal{f}$ Clin Endocrinol 1973;36:715-23.

8 Lifton RP, Dluhy RG, Powers M, et al. A chimaeric 11-betahydroxylase/aldosterone synthase gene causes glucocorticoid-remediable aldosteronism and human hygertension. Nature 1992;355:262-5.

9 Sertension. Nature 1992;355:262-5. Snyder PM, Mcdonald FJ, Stokes JB, Welsh MJ. Membrane topology of the amiloride-sensitive ep
nel. $\mathcal{F}$ Biol Chem 1994;269:24379-83.

10 Canessa CM, Schild L, Buell G, et al. Amiloride-sensitive epithelial $\mathrm{Na}^{+}$channel is made of three homologous subunits. Nature 1994;367:463-7.

11 Shimkets RA, Warnock DG, Bositis CM, et al. Liddle's syndrome: heritable human hypertension caused by mutations in the beta subunit of the epithelial sodium channel. Cell 1994;79:407-14.

12 Hansson JH, Nelson-Williams C, Suzuki H, et al. Hypertension caused by a truncated epithelial sodium channel gamma subunit: genetic heterogeneity of Liddle syndrome. Nat Genet 1994;11:76-82.

13 Mackay K, Byers PH, Dalgleish R. An RT-PCR-SSCP screening strategy for detection of mutations in the gene encoding the $\alpha 1$ chain of type I collagen: application to four patients with osteogenesis imperfecta. Hum Mol Genet 1993;8:1 155-60.

14 Brown MJ. Hypertension. BMF 1997;7089:1258-61. 